\title{
ARTíCULO \\ Prevalencia de las principales enfermedades infecciosas en el camarón blanco Penaeus vannamei cultivado en el Golfo de Nicoya, Costa Rica
}

\author{
Prevalence of the principal infectious diseases in cultured white shrimp \\ Penaeus vannamei in Nicoya Gulf, Costa Rica
}

\begin{abstract}
Nelson Peña-Navarro ${ }^{1 *}$ y Alexander Varela-Mejías ${ }^{1}$
${ }^{1}$ Universidad Técnica Nacional (UTN), Dirección de Investigación, Puntarenas, 148-5400 Puntarenas, Costa Rica. *npena@utn.ac.cr

Abstract.- The largest number of shrimp farms in Costa Rica are located in the Pacific Coast's Gulf of Nicoya. In recent years, these farms have been affected by various diseases that damage the overall health of cultured shrimp. The research objective was to determine the prevalence of the main diseases in 3 different areas of the Gulf of Nicoya (Costa Rica) where Penaeus vannamei specie is produced. From August to October 2013 and February to May 2014, 3 farms were sampled in the region of Nicoya, encoded as F1, F2 y F3; 30 organisms were collected to be analyzed according to climatological season. Diagnostic methodological procedures (clinical examinations, bacteriology of hemolymph, histology and molecular analysis for the viruses WSSV, IHHNV, TSV and YHV) were done on each organism to determine the distinctive clinical signs of the diseases. An average prevalence of $2.22 \%$ for IHHNV, $13.33 \%$ for NHP, 32.78\% for epicommensals, 33.89\% for vibriosis, $100 \%$ for gregarines and $0 \%$ for viruses WSSV, TSV and YHV was found. For F1 and only in summer, IHHNV had the lowest prevalence with $13.33 \%$. Furthermore, in addition to gregarines, one of the highest prevalence was obtained in the F3 during winter. This particular finding corresponded to diseases associated to epicommensals with $63.33 \%$. In addition, the relationship between the prevalence of diseases within sampling site and the presence of diseases taking into account specific site and sampling date was analyzed. There is not enough evidence to establish a clear dependence among variables evaluated.
\end{abstract}

Key words: White spot syndrome virus, parasites in shrimp, shrimp viral diseases, epidemiological surveillance, vibriosis disease

\begin{abstract}
Resumen.- El Golfo de Nicoya de Costa Rica, concentra la mayor cantidad de fincas camaroneras del país, las cuales en los últimos años se han visto afectadas por diversas patologías que dañan el estado sanitario general de los camarones cultivados. La presente investigación determinó la prevalencia de las principales enfermedades en 3 sectores del Golfo de Nicoya (Costa Rica), donde se produce la especie Penaeus vannamei. Entre agosto y octubre del 2013 y entre febrero y mayo de 2014 , se muestrearon 3 fincas en la región de Nicoya, codificados como F1, F2 y F3. Se obtuvieron 30 organismos de cada una y por cada estación climatológica analizada. A cada camarón se le realizaron procedimientos para determinar los signos clínicos característicos de las enfermedades más comunes, que incluyeron exámenes clínicos, bacteriología de hemolinfa, histología y análisis molecular para los virus WSSV, IHHNV, TSV y YHV. Se determinó una prevalencia promedio de 2,22\% para IHHNV, 13,33\% para NHP, 32,78\% para epicomensales, 33,89\% para vibriosis, 100\% para gregarinas y 0\% para los virus WSSV, TSV y YHV. Para la F1 y sólo en verano, IHHNV presentó la prevalencia más baja con $13,33 \%$ y aparte de las gregarinas, una de las prevalencias más altas se dio en la F3 durante invierno y correspondió a las enfermedades asociadas con epicomensales en un 63,33\%. Se analizó la relación entre las prevalencias de las enfermedades con el sitio de muestreo y la presencia de las enfermedades por sitio y fecha de muestreo y se determinó que no hay evidencia suficiente para determinar relación entre las variables analizadas.
\end{abstract}

Palabras clave: Virus del síndrome de la mancha blanca, parásitos en camarón, enfermedades virales en camarones, vigilancia epidemiológica, enfermedades por Vibrio spp.

\section{INTRODUCCIÓN}

Los diferentes sistemas de producción de camarones están determinados en primera instancia por la densidad de siembra utilizada así como el manejo de los parámetros físico-químicos del agua y la cantidad y tipo de alimento analizado en el sistema. Sin embargo, el factor más importante está en dependencia con la cantidad de agua utilizada proveniente de los esteros (Peña 2009).
En los últimos años las densidades de siembra se han incrementado y el manejo de los parámetros productivos ha venido en detrimento. Esto ha propiciado la proliferación de enfermedades y la aparición de nuevas patologías que afectan directamente la rentabilidad de los sistemas productivos de camarón. Esto ha tenido como consecuencia la disminución de las exportaciones del producto, generando la necesidad de 
investigar las enfermedades presentes en sistemas y camarones de cultivo (Morales et al. 2011).

En la actualidad existen 9 enfermedades de crustáceos que han sido declaradas de notificación obligatoria por la Organización Mundial de Sanidad Animal (OIE), que incluyen las 8 publicadas en el Código Acuático y la nueva Enfermedad de la Necrosis Aguda del Hepatopáncreas (AHPND por sus siglas en inglés) que fue recientemente incorporada. Lightner (2011) sostiene que del total de enfermedades que afectan la producción de camarón a nivel mundial, las más destacadas son IHHNV (virus de la necrosis hipodérmica y hematopoyética infecciosa), TSV (virus del síndrome de Taura), WSSV (virus de la mancha blanca), YHV (virus de la cabeza amarilla), e IMNV (virus de la mionecrosis infecciosa). También sugiere que enfermedades virales como el IHHNV, TSV y WSSV han sido introducidas de país en país por medio del transporte de camarones vivos, ocasionando pérdidas de millones de dólares.

Actualmente, la especie más explotada es el camarón blanco del Pacífico Penaeus (Litopenaeus) vannamei Boone, 1931, el cual genera anualmente en el mundo un equivalente a 9 billones de dólares, seguida por el $P$. monodon con 3 billones de dólares por año (Stentiford 2011). De la misma manera, Moss et al. (2012) mencionan que a nivel mundial se produjeron 3,5 millones de toneladas métricas de camarón durante el 2009, las cuales rondaron los 14,6 billones de dólares, aunque enfatiza que la industria se encuentra plagada de enfermedades.

Por su parte, Flegel (2012) ha estimado que el 60\% de las enfermedades que aparecen en la acuicultura del camarón están relacionadas con virus y $20 \%$ a bacterias; el resto se distribuye entre hongos y parásitos. Se ha destacado que WSSV y YHV son las más letales, siguiendo el IMNV en importancia para $P$. vannamei. Además, indica que en los últimos años se ha dado la aparición de nuevas enfermedades, como la deformación del segmento abdominal (ASDD); en P. monodon se detectó después de WSSV y el YHV, el síndrome del crecimiento lento en monodon (MSGS), como una de las más patogénicas. En América, la mayor epidemia de la enfermedad de las manchas blancas comenzó en Nicaragua, Honduras y Guatemala en 1999, siendo en la actualidad una enfermedad endémica de las regiones de cultivo de camarón en todo Centro y Sur América (Peeler 2012). Anivel mundial, desde 1990, WSSV ha dejado pérdidas por más de 10 billones de dólares (Stentiford 2011).

Resultado de lo anterior, se han realizado esfuerzos importantes para determinar la prevalencia de enfermedades en las diversas regiones del planeta, tal como lo realizaron Morales et al. (2011), donde encontraron la presencia de 12 enfermedades alrededor de 8 regiones de Latinoamérica. Por otro lado, Alfaro et al. (2010), localizaron en langostinos silvestres la prevalencia de enfermedades como NHP, IHHNV, BP, WSSV y TSV, manifestando la posibilidad de que estos organismos sean vectores de enfermedades para los sistemas de cultivo de camarón. Por tal motivo, el objetivo del presente estudio fue determinar la prevalencia de enfermedades que afectan el cultivo de camarón blanco (P. vannamei) en sistemas productivos ubicados en el Golfo de Nicoya, Costa Rica.

\section{Materiales Y MÉTODOS}

\section{Área de estudio}

El estudio se realizó en la principal zona de producción de camarones de Costa Rica, entre agosto y octubre de 2013 y febrero y mayo de 2014, siendo el Golfo de Nicoya el área donde se seleccionaron las fincas utilizadas para la recolección de las muestras. Las fincas muestreadas se codificaron con las siglas F1, F2 y F3, mismas que se encuentran específicamente en las regiones de Quebrada Honda, Porosal y Níspero, con una elevación promedio de 3 m.s.n.m (Tabla 1).

Tabla 1. Ubicación de las fincas de camarón de cultivo muestreadas en el Golfo de Nicoya, Costa Rica, 2014 / Location of farms sampled with shrimp farming in the Gulf of Nicoya, Costa Rica, 2014

\begin{tabular}{|c|c|c|c|c|}
\hline Finca & Coordenadas geográficas & $\begin{array}{c}\text { Temperatura } \\
\text { media anual }\left({ }^{\circ} \mathrm{C}\right)\end{array}$ & $\begin{array}{c}\text { Precipitación } \\
\text { media anual }(\mathrm{mm})\end{array}$ & $\begin{array}{l}\text { Tipo de } \\
\text { cultivo }\end{array}$ \\
\hline $\mathrm{F} 1$ & $10^{\circ} 12^{\prime} 43^{\prime \prime} \mathrm{N}, 85^{\circ} 13^{\prime} 19^{\prime \prime O}$ & 26,4 & 2011 & $\begin{array}{l}\text { Semi- } \\
\text { intensivo }\end{array}$ \\
\hline $\mathrm{F} 2$ & $10^{\circ} 14^{\prime} 40^{\prime} \mathrm{N}, 85^{\circ} 13^{\prime} 36^{\prime \prime O}$ & 26,7 & 1846 & $\begin{array}{l}\text { Semi- } \\
\text { intensivo }\end{array}$ \\
\hline F3 & $10^{\circ} 09^{\prime} 31^{\prime \prime N}, 85^{\circ} 14^{\prime} 59^{\prime \prime O}$ & 26,7 & 1846 & $\begin{array}{c}\text { Semi- } \\
\text { intensivo }\end{array}$ \\
\hline
\end{tabular}




\section{RECOLECCIÓN DE ORGANISMOS}

Se realizaron 2 muestreos para cada finca analizada, uno en invierno, comprendido entre agosto-octubre 2013, y otro durante el verano, entre febrero-mayo 2014. Se recolectaron 30 animales para cada granja según lo recomendado por Lightner (1996), al azar y en 4 diferentes áreas del estanque (Morales 2010). Se visitaron 3 fincas durante 10 meses. En total se extrajeron 180 camarones $P$. vanname $i$, con intervalos de pesos entre 4,4 y 27,6 g, promedio de 13,4 $\pm 1,94 \mathrm{~g}$. El trabajo estuvo sujeto a las épocas de cosechas, que incluyen un periodo de secado y tratamiento de los estanques en ausencia de cultivo.

Los camarones fueron capturados con atarraya de $2 \mathrm{~m}$ de diámetro y ojo de malla de 5 x $5 \mathrm{~mm}$, seleccionados al azar en cuatro áreas del estanque, según la metodología descrita por de Blas \& Muniesa (2014). Estos se almacenaron en contenedores de plástico, con agua del estanque y aireación para mantenerlos vivos hasta su posterior procesamiento. Los camarones fueron revisados detalladamente, siguiendo las técnicas empleadas por Morales et al. (2011).

\section{Examen Clínico}

El examen clínico fue realizado al momento de la recolección de los animales en las fincas establecidas. De acuerdo con la metodología de Cuéllar-Anjel (2008), se examinaron los animales observando: color, tamaño del cuerpo comparado con el resto de la población (enanismo), expansión de cromatóforos, deformidad en rostro, abdomen o apéndices, flexión del músculo abdominal, color de las branquias (amarillas, marrón o negras), color de los apéndices (pereiópodos, pleópodos y urópodos), color de las antenas, presencia de edemas en apéndices u otras partes del cuerpo, transparencia de los músculos del abdomen y del cefalotórax, repleción intestinal (porcentaje del intestino que se encuentra lleno), textura del exoesqueleto (firme o blando), tono del músculo abdominal (firme o flácido) manchas, heridas, color del esófago yestómago (rojizo sugiere canibalismo y mortalidad), presencia de moco sobre la cutícula (liso o áspero al tacto) y laceraciones. Se determinó para ciertas enfermedades el grado de severidad según la guía presentada por CuéllarAnjel (2014).

Para determinar el grado de infestación por epicomensales y parásitos, se utilizó un valor numérico del grado de severidad, donde G0 no presenta signos de infección/infestación, G1 presenta muy pocos epicomensales o gregarinas, justo arriba del límite normal; G2 con presencia baja a moderada de epicomensales o gregarinas, se pueden presentar lesiones e incremento en la mortalidad; G3 con presencia alta de parásitos y lesiones severas; por último G4 con gran cantidad de epicomensales o gregarinas y lesiones severas (Lightner 1996, Morales 2010).

\section{BaCteriología DE HEMOLINFA}

Se empleó la técnica descrita por Cuéllar-Anjel (2008), la cual consistió en utilizar sólo camarones vivos para la prueba. Se desinfectó el área de punción (seno hemolinfático ventral) con alcohol al 70\%, posteriormente, con una jeringa de insulina (1 $\mathrm{mL}$ ) nueva y estéril con aguja hipodérmica, se extrajeron 100 $\mu \mathrm{L}$ de hemolinfa y se sembraron en agar TCBS (tiosulfato citrato bilis sal sacarosa), el cual es un medio de cultivo selectivo diferencial para bacterias del género Vibrio.

Una vez inoculados los $100 \mu \mathrm{L}$ de muestra sobre el agar y en condiciones asépticas se extendió circularmente mediante el uso de un asa de Drigalski previamente flameada, para obtener una distribución homogénea del inóculo. Seguidamente se tapó la caja de Petri y se invirtió e incubó a una temperatura de $30^{\circ} \mathrm{C}$ por $24 \mathrm{~h}$. Se revisó la presencia o ausencia de bioluminiscencia a las $18 \mathrm{~h}$. Posteriormente, se cuantificaron las unidades formadoras de colonias (UFC) que se presentaron en cada placa, utilizando como método la observación directa (a trasluz).

\section{Histología}

La histología se realizó en la sección de Patologías del Laboratorio Nacional de Servicios Veterinarios (LANASEVE), Servicio Nacional de Salud Animal (SENASA) del Ministerio de Agricultura y Ganadería (MAG) de Costa Rica.

Para la fijación, preparación de los animales e histología, se siguió la metodología descrita por Cuéllar-Anjel (2014). Se utilizó el fijador de Davidson en animales vivos o moribundos, nunca muertos, inyectándose en hepatopáncreas, cefalotórax y en músculo. Luego, se realizó un corte en la cutícula, sobre la línea lateral, con la finalidad de facilitar la penetración del fijador; posteriormente cada camarón se sumergió en el mismo fijador manteniendo una relación de 1:10 (camarón-fijador) durante 12-24 h. Por último, se pasaron a etanol al $70 \%$ hasta ser procesados por histología, tiempo que no excedió los 15 días.

Posterior a la fijación, se remitió la muestra al LANASEVE para su procesamiento, realizando la deshidratación de los tejidos, inclusión en parafina, bloqueo y cortes con un micrótomo a $3 \mathrm{~mm}$ de espesor. Los cortes se colocaron en un baño de recuperación y los tejidos seleccionados se capturaron con una lámina portaobjetos. Por último, el método de tinción utilizado fue el de Hematoxilina de Mayer-Bennett y Floxina/ Eosina (H\&E) (Lightner 1996). Se analizaron los cortes observándose en un microscopio óptico con aumento de 40X, 100X y 400X. 


\section{ANÁLISIS MOLECULAR}

El análisis molecular se realizó en el área de Biología Molecular y Genética del Laboratorio de Seguridad (LSE), que forma parte del Laboratorio Nacional de Servicios Veterinarios (LANASEVE), Servicio Nacional de Salud Animal (SENASA) del Ministerio de Agricultura y Ganadería (MAG) de Costa Rica.

Se realizaron análisis para los virus de WSSV, TSV, IHHNV y YHV. Se extrajo tejido de las branquias y pleópodos de cada uno de los camarones, mismos que fueron fijados en etanol al $95 \%$.

Para la extracción de ácidos nucleicos de los virus de Taura y Cabeza Amarilla, se empleó el protocolo DV-LSE-PT-003IN-001 y para detectar el virus de la Mancha Blanca se usó el protocolo DV-LSE-PT-003-IN-002 (SENASA 2014) ${ }^{1}$. La amplificación de los ácidos nucleicos, siguieron los protocolos emitidos por LANASEVE (SENASA 2014) ${ }^{1}$.

\section{Prevalencia de enfermedades}

Para obtener la prevalencia de las enfermedades se tomó en consideración el trabajo de Bush et al. (1997) y la fórmula empleada por Morales et al. (2011).

$$
\text { Prevalencia }=\frac{N^{\circ} \text { hospederos con patógenos, parásitos o epibiontes }}{N^{\circ} \text { total de hospederos }} \cdot 100
$$

Adicionalmente, se tomó en consideración el muestreo aleatorio en 4 áreas diferentes del estanque para la obtención de la prevalencia y se garantizó el porcentaje de confianza según Morales et al. (2010).

\section{AnÁlisis estadístico}

Para determinar la relación entre la prevalencia de las enfermedades encontradas con el sitio de muestreo, se utilizaron tablas de contingencia con las frecuencias observadas, con un nivel de confianza de $\alpha=0,05$. La hipótesis nula sugiere que el sitio y las enfermedades son independientes entre sí. Para comprobar esto se utilizó el estadístico Chi-cuadrado, siguiendo a Morales (2011). Por otro lado, para determinar el efecto del clima (invierno y verano), se realizó el mismo análisis pero con tablas de contingencia tridimensionales. En ambos casos se rechazó Ho si /Zc/ / /Zt/, y no se rechazó si /Zc/ $</ Z \mathrm{Zt} /$.

$$
x_{c}^{2}=\sum_{i=l}^{f} \sum_{j=l}^{c} \frac{\left(O_{i j}-E_{i j}\right)^{2}}{E_{i j}}
$$

${ }^{1}$ SENASA 2014. Detección de enfermedades del camarón por PCR. Servicio Nacional de Salud Animal, San José, Costa Rica.<http://www.senasa.go.cr/> donde,

$$
E_{i j}=\frac{N_{i} * N_{j}}{N}
$$

$\mathrm{Ni}$ : Suma de valores de la fila 'i'

$\mathrm{Nj}$ : Suma de valores de la fila ' $\mathrm{j}$ '

$$
x_{c}^{2}=(f-1)(c-1) \text { grados de libertad }
$$

$f:$ total de filas

$c$ : total de columnas

Adicionalmente, se calcularon los intervalos de confianza para cada prevalencia obtenida, aplicando la siguiente fórmula:

$$
L i=p \pm Z_{\alpha / 2} \sqrt{\frac{(p * q)}{n}}
$$

Con respecto a los intervalos de confianza obtenidos para cada uno de los indicadores de las patologías, se estimaron valores tomando en cuenta un nivel de confianza del 95\%. Para cada una de las patologías los estimadores se detallan en los resultados, además se indica el estimador puntual de la prevalencia de cada enfermedad.

\section{Resultados}

Durante el periodo de estudio, se identificaron características externas que son evidencia de la presencia de varias enfermedades, tales como cromatóforos expandidos, estómago de coloración rojiza debido a canibalismo, urópodos rojos, deformidad del músculo, pleópodos y pereiópodos de color amarillo y cutícula suave. Particularmente, para este estudio se logró determinar en las dos estaciones climatológicas analizadas la presencia de 5 enfermedades, su respectiva prevalencia y sus intervalos de confianza (Tabla 2).

Asimismo, al obtener el promedio general de la prevalencia para la zona en análisis de estudio (Fig. 1), se logró determinar cuáles son las principales enfermedades que están afectando los sistemas de cultivo de camarón para esa zona particular en Costa Rica. De acuerdo con esto, se describen a continuación los resultados obtenidos para las enfermedades que se manifiestan actualmente en los sistemas de cultivo.

\section{VIRUS}

No se obtuvo la confirmación de la presencia de los principales virus analizados para Costa Rica mediante el análisis molecular, específicamente para las patologías que han tenido presencia a través de los años en las producciones de camarón del país. La 
histopatología reconfirmó la ausencia de lesiones tisulares causadas por los principales virus en estudio. Los resultados de PCR e histología mostraron en la investigación que las enfermedades por el virus del Síndrome de Taura (TSV), Virus de las manchas blancas (WSSV) y Virus de la cabeza amarilla (YHV) presentaron una prevalencia del $0 \%$ para todos los casos.

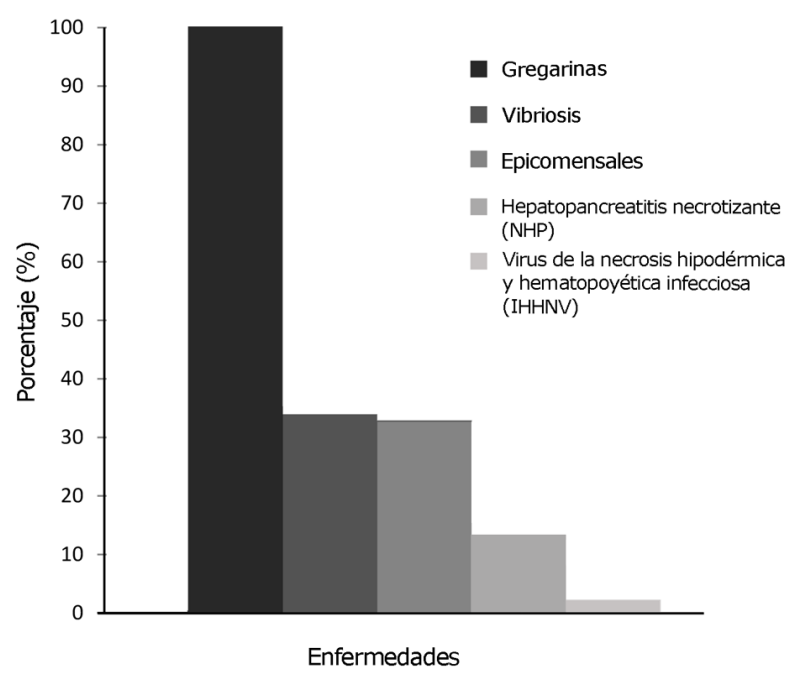

Figura. 1. Promedio de prevalencia de las enfermedades más importantes encontradas en fincas de camarón de cultivo en 3 zonas del Golfo de Nicoya, Costa Rica, 2014 / Average prevalence of the most important diseases found in cultured penaeid shrimp in 3 areas of the Gulf of Nicoya, Costa Rica, 2014
Por su parte, el virus de la necrosis hipodérmica y hematopoyética infecciosa (IHHNV) presentó sólo para la finca F1 una prevalencia del 13,33\% y específicamente para la época de verano. El diagnóstico realizado a partir del estudio histopatológico del presente estudio mostró para IHHNV epitelio gástrico con cariomegalia (Fig. 2C) y cuerpos de inclusión en tejido branquial (Fig. 2D), resultado que fue confirmado por medio del análisis de PCR.

Dentro de los análisis preliminares se determinó la presencia de camarones con deformaciones en rostro y caparazón áspero o rugoso, mismos que fueron los primeros signos que determinaron la presencia de IHHNV en las fincas camaroneras que fueron objeto de estudio. Los intervalos de confianza obtenidos están entre $0,06-4.34 \%$, lo que demostró que su presencia se da con un bajo rango en las producciones de camarón de Costa Rica.

\section{B ACTERIAS}

La prevalencia general fue del $30 \%$ (Tabla 2). Tanto en invierno como en verano existieron casos de vibriosis en los camarones, y particularmente la época de invierno mostró para F1, F2 y F3 una mayor prevalencia que en verano, siendo 33,3, 53,3 y $50 \%$ respectivamente. Los intervalos de confianza obtenidos se encontraron entre $26,97-40,80$, lo que demuestra que su presencia se da con gran amplitud en las fincas camaroneras.

Tabla 2. Prevalencia y valores promedio de las enfermedades más importantes en fincas de camarón cultivado en 3 zonas del Golfo de Nicoya, Costa Rica, 2014 / Prevalence and average values of the most important diseases in cultured penaeid shrimp in 3 areas of the Gulf of Nicoya, Costa Rica, 2014

\begin{tabular}{|c|c|c|c|c|c|c|c|c|c|c|c|}
\hline \multirow{3}{*}{ Enfermedades } & \multicolumn{11}{|c|}{ Prevalencia (\%) } \\
\hline & \multicolumn{3}{|c|}{$\mathrm{F} 1$} & \multicolumn{3}{|c|}{$\mathrm{F} 2$} & \multicolumn{3}{|c|}{ F3 } & \multirow{2}{*}{ PG } & \multirow{2}{*}{ IC } \\
\hline & I & $\mathrm{V}$ & $\mathrm{P}$ & I & $\mathrm{V}$ & $\mathrm{P}$ & I & $\mathrm{V}$ & $\mathrm{P}$ & & \\
\hline Gregarinas & 100 & 100 & 100 & 100 & 100 & 100 & 100 & 100 & 100 & 100 & 100 \\
\hline Vibriosis & 33,33 & 16,66 & 25,00 & 53,33 & 23,33 & 38,33 & 50,00 & 26,66 & 38,33 & 33,89 & $26,97-40,80$ \\
\hline Epicomensales & 30,00 & 23,33 & 26,67 & 16,66 & 40,00 & 28,33 & 63,33 & 23,33 & 43,33 & 32,78 & $25,92-39,64$ \\
\hline NHP & 16,66 & 30,00 & 23,33 & 0 & 20,00 & 10,00 & 3,33 & 10,00 & 6,67 & 13,33 & $8,36-18,30$ \\
\hline IHHNV & 0 & 13,33 & 6,67 & 0 & 0 & 0 & 0 & 0 & 0 & 2,22 & $0,06-4,34$ \\
\hline TSV & -- & -- & -- & -- & -- & -- & -- & -- & -- & -- & -- \\
\hline WSSV & -- & -- & -- & -- & -- & -- & -- & -- & -- & -- & -- \\
\hline YHV & -- & -- & -- & -- & -- & -- & -- & -- & -- & -- & -- \\
\hline
\end{tabular}

F1: Finca 1, F2: Finca 2, F3: Finca 3

I: Invierno, V: Verano, P: Promedio, PG: Promedio General, IC: Intervalo de confianza 

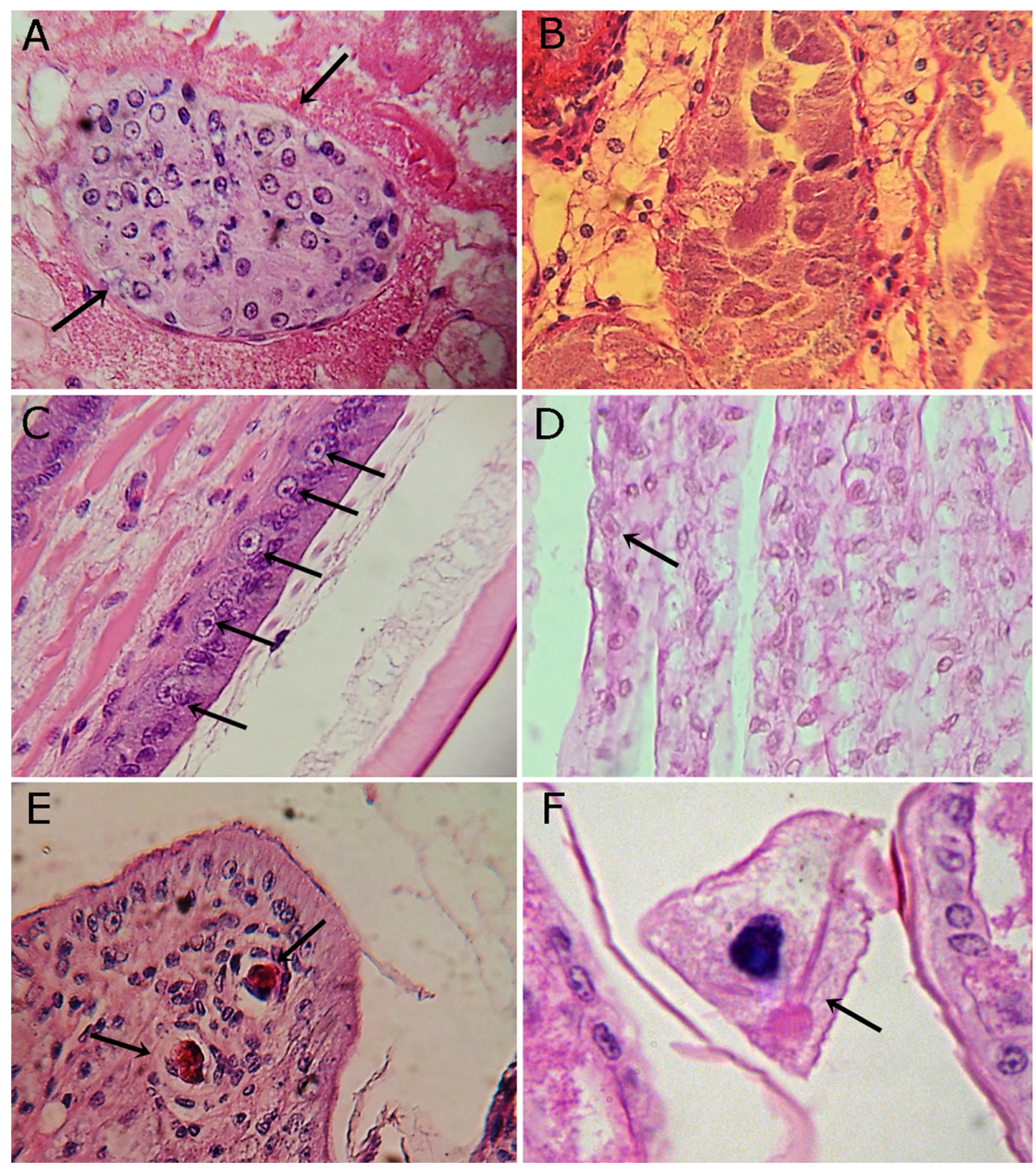

Figura. 2. Cortes histológicos de Penaeus vannamei con lesiones producidas por diferentes enfermedades. A) Tejido conectivo perigástrico con presencia de esferoide ectópico. B) Tejido muscular presentando infiltración hemocítica moderada en espacios intrafasciculares. C) Epitelio subgástrico, algunas células presentan cariomegalia. D) Tejido branquial con cuerpo de inclusión intranuclear, eosinofílico. E) Tejido conectivo perigástrico con nódulos hemociticos multifocales, melanizados y necróticos. F) Cámara branquial con presencia de Acineta sp. Tinción H\&E / Histological sections of Penaeus vannamei with lesions caused by different diseases. A) Connective tissue perigastric containing ectopic spheroid. B) Muscle tissue with moderate haemocytic infiltration in intrafascicular spaces. C) Gastric epithelium with cariomegalia in some cells. D) Gill tissue with intranuclear, eosinophilic inclusion body. E) Connective tissue perigastric with hemocytic multifocal nodules, melanized and necrotic. F) Gill chamber with presence of Acineta sp. H\&E staining

Dentro del estudio histológico se determinaron una serie de lesiones generadas por infecciones bacteriales, dentro de estas están la presencia de esferoides (Fig. 2A), nódulos melanizados y necróticos en tejido conectivo perigástrico (Fig. 2E), infiltración hemocítica en espacios intrafasciculares del tejido muscular (Fig. 2B), esferoides ectópicos en palpo mandibular, con evidencia de núcleos picnóticos y necrosis (Fig. 3B), y nódulos hemocíticos en lamela branquial con melanosis.
Por otro lado, se determinó una prevalencia baja para NHP con presencia en todas las fincas de estudio, el promedio general fue para F1 (23,33\%), F2 (10\%) y F3 (6,67\%); solo para F2 no presentó ningún caso en el invierno. Los intervalos de confianza obtenidos se encontraron entre 8,36 y 18,30 y se determinó una prevalencia general promedio de $13,33 \%$. 

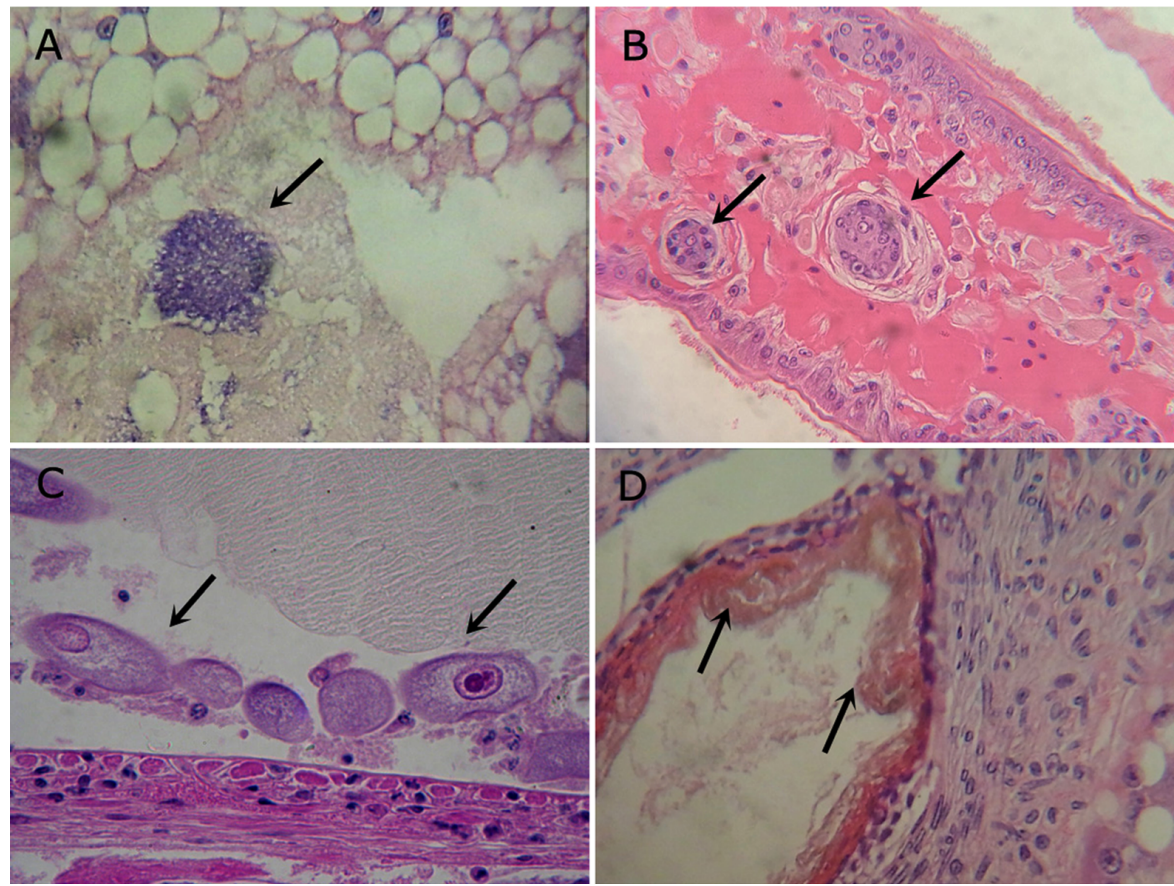

Figura. 3. Cortes histológicos de Penaeus vannamei con lesiones producidas por diferentes enfermedades. A) Agregación bacterial en tejido conectivo de los espacios intertubulares en hepatopáncreas. B) Esferoides ectópicos en palpo mandibular, se evidencian núcleos picnóticos y necrosis. C) Gregarinas en intestino medio. D) Túbulo hepatopancreático con melanizaciones, múltiples capas de hemocitos concéntricos y atrofia epitelial. Tinción H\&E / Histological sections of Litopenaeus vannamei with lesions caused by different diseases. A) Bacterial aggregation in connective tissue of the interlobular spaces in hepatopancreas. B) Ectopic spheroids in mandibular palp, pyknotic nuclei and necrosis are evident. C) Gregarines in midgut. D) Hepatopancreatic tubule with melanization, multiple concentric layers of hemocytes and epithelial atrophy. H\&E staining

Se determinó por medio del análisis histológico la presencia de necrosis hepatopancreática séptica (SHPN) en los camarones analizados, encontrando agregación bacterial en tejido conectivo de los espacios intertubulares del hepatopáncreas (Fig. 3A) y túbulos del hepatopáncreas necróticos, melanizados, con múltiples capas de hemocitos concéntricos y atrofia epitelial (Fig. 3D).

Es importante considerar que se presentó una diferencia notable entre el promedio de colonias sacarolíticas y no sacarolíticas de acuerdo a la estación del año en que fueron tomadas las muestras. En invierno el análisis de la hemolinfa presentó un mayor crecimiento de colonias no sacarolíticas en comparación al verano, siendo para las fincas F1, F2 y F3 de $16,66,26,66$ y $36,66 \%$ en invierno y de $16,16,66$ y $16,66 \%$ en verano, respectivamente. Dado esto, en la época de verano la finca F3 mostró un 62,5\% de muestras con luminiscencia, $\mathrm{F} 1$ un $20 \%$ y F2 alrededor de un 15\%. Estas mismas fincas no presentaron bacterias luminiscentes en invierno.

\section{Epicomensales}

Los epicomensales se muestran como una de las parasitosis más importantes con una prevalencia alta. Para todos los casos analizados se presentó tanto en invierno como en verano. F1 y F2 mostraron prevalencias similares de 26,67 y $28,33 \%$, respectivamente. Particularmente, F3 tuvo una prevalencia de $43,33 \%$, superando por más de un $15 \%$ a las otras fincas analizadas. Se obtuvieron en el estudio grados de severidad desde G1 hasta G4.

Se identificó la presencia de diferentes especies de protozoarios como Zoothamnium sp., Acineta sp. (Fig. 2F), y Epistylis sp., en casos severos se observaron lesiones asociadas en lámelas branquiales, descritas principalmente como melanosis en las secciones basales de las branquias. Los intervalos de confianza obtenidos se encontraron entre 25,9239,64 , con un promedio general de prevalencia del $32,78 \%$. 


\section{Gregarinas}

En todas las fincas analizadas, tanto en verano como en invierno, se presentó una prevalencia del 100\%. De las 180 muestras analizadas, cada una de las observaciones presentó gregarinas en sus diversos estadios, con grados de severidad desde G1 hasta G4.

En el montaje en fresco se encontraron gregarinas en las heces extraídas del intestino medio de los camarones, mismas que fueron visualizadas bajo el microscopio, utilizando aumento de 10X y 20X. Anivel histológico, se observaron estos parásitos en el intestino medio (Fig. 3C).

\section{Análisis estadístico}

Se determinó que no se tiene evidencia estadísticamente significativa $(P<0,05)$ para afirmar que las enfermedades son independientes del sitio. Del mismo modo sucede con la presencia de las enfermedades por sitio y fecha de muestreo. Esto quiere decir que no se determinó relación entre la presencia de las enfermedades, el lugar donde se tomaron las muestras y la estación climatológica analizada.

\section{Discusión}

En Costa Rica y especialmente en el Golfo de Nicoya, se ha dado la aparición de una gran cantidad de cuadros patológicos desde hace varios años (Varela \& Peña 2013) que han provocado el deterioro de la producción en los cultivos de. $P$ vannamei. Para Costa Rica, la lista de enfermedades de declaración obligatoria incluye a TSV, WSSV, YHV y el IHHNV $\left(\right.$ MAG 2008) ${ }^{2}$; sin embargo, a nivel internacional se incluyen además IMNV, NHP y AHPND (OIE 2015) ${ }^{3}$.

En los últimos años, los principales efectos negativos en la producción en Costa Rica están asociados con los virus, siendo WSSV el principal causante de altas mortalidades; no existen reportes oficiales para casos de TSV o YHV. Sin embargo, esta investigación ha sorprendido por presentar una prevalencia del $0 \%$ para los principales virus analizados, contra datos presentados por Morales et al. (2011) quiénes indican en su estudio, que para Costa Rica se han reportado prevalencias de WSSV de 15 al 100\%; posiblemente debido a larvas más resistentes a esta enfermedad o incluso a una época con características particulares asociados a temperatura, precipitación y salinidad. Ciertas regiones de Centroamérica con características productivas similares a Costa Rica, como Nicaragua, Guatemala, Honduras y Panamá, tuvieron prevalencias entre 15 y $100 \%$ para WSSV, demostrado su presencia en prácticamente todos los sistemas productivos (Morales et al. 2011).

Otras regiones productivas como la India obtuvieron para diferentes épocas del año, prevalencias de WSSV desde el 0 hasta 31,6\% en Penaeus monodon (Chakrabarty et al. 2014)

El virus de la necrosis hipodérmica y hematopoyética infecciosa (IHHNV) se detectó únicamente en la finca F1 con una baja prevalencia, coincidiendo con Morales et al. (2011), con una prevalencia promedio de $13,4 \%$ para 8 regiones diferentes de Latinoamérica. Sin embargo, aunque sólo se presentó este caso en particular, se tienen registros de la aparición de cuadros clínicos que incluyen deformidades cuticulares, crecimiento reducidoe irregular en fincas cercanas y en periodos distintos a los mencionados en este estudio; características que son compatibles con del síndrome de la deformidad y enanismo (RDS, y que es causado por el virus IHHNV en P. vannamei).

Un estudio efectuado durante el 2009 en México, mostró la presencia de IHHNV y TSV en camarones silvestres, específicamente en $P$. setiferus y $P$. aztecus, donde obtuvieron una prevalencia de 6,6 y 4,4\%, respectivamente para TSV e IHHNV (Guzmán et al. 2009). Macías et al. (2014), determinaron una prevalencia media para IHHNV del 19,5\% en muestras de diversos invertebrados obtenidas en fincas camaroneras ubicadas en la Costa Pacífico de México. De este estudio se desprende la alerta sobre el riesgo que se presentan en las fincas camaroneras ubicadas en el Golfo de México y donde eventualmente se podrían generar las mismas condiciones para el Golfo de Nicoya.

En Brasil, la intensificación de la producción ha provocado la confirmación de IHHNV y IMNV, por medio de PCR (Teixeira et al. 2011). Mismo resultado que fue demostrado en el estudio de da Silva et al. (2010), donde por medio de análisis histopatológicos confirmaron IMNV como una de las patologías más críticas en el noreste de Brasil. Por su parte, Braz et al. (2009) obtuvieron una prevalencia de IHHNV desde el 9,4\% hasta el $81 \%$ en 7 diferentes granjas del noreste de Brasil. Cabe destacar, que el crecimiento acelerado y descontrolado de la industria generó la aparición de múltiples virus con una acelerada dispersión (Pantoja \& Lightner 2014).

\footnotetext{
${ }^{2}$ MAG. 2008. Listado de enfermedades animales de declaración obligatoria. Ministerio de Agricultura y Ganadería, San José, Costa Rica. <http://www.mag.go.cr/legislacion/2008/de-34669.pdf>

${ }^{3}$ OIE. 2015. Enfermedades, infecciones e infestaciones de la Lista de la OIE en vigor en 2015. Organización Mundial de Sanidad Animal. <http://www.adshoyahuesca.org/Descargas/enfermedades_de_declaraci\%C3\%93n_obligatoria/LISTA\%20ENFERMEDADES \%200IE\%202015.pdf>
} 
Morales (2010) indican en sus análisis histológicos para IHHNV, que existen cuerpos de inclusión intranucleares, prominentes, eosinofílicos en células de tejidos de origen ectodérmico como es el caso de branquias y tejido estomacal. En concordancia con lo encontrado en las muestras procesadas en este estudio (Fig. 2C y 2D), en estos tejidos no detectaron los típicos cuerpos de inclusión del IHHNV, pero si se presentaron núcleos hipertrofiados sugiriendo estadíos iniciales de desarrollo de inclusiones, diagnóstico que fue posteriormente confirmado mediante PCR.

Del mismo modo en que los virus han afectado la industria camaronícola, durante el último quinquenio, las bacterias han incrementado su capacidad para generar daños y por la aparición de nuevas enfermedades, donde Vibrio sp. ha sobresalido. Yano et al. (2014) obtuvieron prevalencias para V. cholerae del 94\%, V. parahaemolyticus del $38 \%$ y V. vulnificus del $12,5 \%$ al determinar la presencia de estas bacterias en camarones de cultivo en Tailandia.

Peña \& Varela (2015) detectaron que camarones de la especie $P$. vannamei infectado con V. parahaemolyticus, mostraron en su análisis histológico reacciones inmunológicas y efectos citopáticos similares a la presente investigación, por lo que se confirma el efecto perjudicial de las bacterias del genero Vibrio sp.

Estudios previos realizados en Latinoamérica indican una prevalencia promedio de $19,05 \%$ asociada a bacterias como V. campbellii, V. parahaemolyticus, V. brasiliensis y Streptococos spp. (Morales et al. 2011). Algunos estudios confirman la distribución de la bacteria que causa la necrosis aguda del hepatopáncreas en $P$. vannamei cultivados en Sonora y Sinaloa, México (Ibarra et al. 2007). La prevalencia para esta enfermedad se mostró en un rango de 14,6-59,5\% y $5-42 \%$ para Sonora y Sinaloa, respectivamente.

A nivel de parámetros climatológicos y productivos en las fincas de estudio, durante el verano se registraron temperaturas superiores a los $35^{\circ} \mathrm{C}$, escasez de lluvias y una conversión alimenticia elevada. Es probable que se desarrolle un ambiente propicio para la generación de colonias de bacterias potencialmente patógenas, como las que provocan luminiscencia. A la vez, se registraron mortalidades por hipoxias constantes a través del ciclo productivo, alcanzando niveles mínimos de $1 \mathrm{mg} \mathrm{L}^{-1}$ de oxígeno durante las primeras horas del día. Morales \& Gómez-Gil (2014) indican que las fluctuaciones de la temperatura, salinidad, oxígeno y $\mathrm{pH}$, entre otros, influyen en las comunidades bacterianas, lo que genera la proliferación de patógenos que provocan mortalidades en los camarones de cultivo. Aunque no se logró inferir las especies de bacterias que proliferaron en la investigación, los autores anteriores mencionan dentro de las principales a $V$. harveyi, $V$. parahaemolyticus, V. penaeicida, V. nigripulchritudo, $V$. campbellii, Micrococcus sp., y Streptococcus sp.

Para finales del 2014 en las fincas camaroneras de Costa Rica, y luego de obtener los resultados anteriormente expuestos, se dio uno de los principales episodios registrados por problemas con bacterias, identificando en producciones de camarón de forma combinada, la presencia de Hepatopancreatitis necrotizante (NHP), Necrosis séptica del hepatopáncreas (SHPN) y el virus de la mancha blanca (WSSV).

Otras patologías de interés encontradas en este estudio, se asociaron con la presencia de epicomensales y gregarinas. Los resultados presentados en este estudio concuerdan con lo expuesto por Morales et al. (2011), cuyo diagnóstico se asocia con necrosis y melanosis de las branquias. El estudio de Morales et al. (2011) presentó grados de severidad de G1 y G2, con una prevalencia promedio del $13,1 \%$, muy por debajo de los resultados de prevalencia obtenidos en la presente investigación. Por otro lado, Morales et al. (2011) indica una prevalencia para gregarinas de $8,3 \%$ en 8 regiones analizadas de Latinoamérica, con un máximo de $20 \%$ y un mínimo de $5 \%$. Para este estudio, se observó presencia constante de gregarinas en grados G1 y G2; siendo identificada la especie Nematopsis sp. Esta parasitología se asocia a baja calidad de aguas e incrementa en altas densidades de siembra en los sistemas de cultivo, entre otras posibles causas.

Cuéllar-Anjel (2014) menciona la presencia de gregarinas y epicomensales en la región y otros parásitos como microsporidios, haplosporidios y metazoarios. Estos últimos no se detectaron en este estudio. Generalmente los protozoarios son los que más afectan al localizarse en branquias, apéndices, exoesqueleto y tracto digestivo. Al igual que el estudio de Peña et al. (2013), se encontraron ectoparásitos en lamelas branquiales tales como Zoothamnium sp. y Epistylis sp. así como la presencia de endoparasitosis con niveles de hasta 100 gregarinas por campo visual, lo que indica una gran infestación de parásitos en los camarones analizados.

En términos generales, para reducir y controlar las mortalidades causadas por cada una de las enfermedades existentes en las producciones de camarón, se hace necesaria la implementación de prácticas de manejo adecuadas. Tal como indica Morales et al. (2011), prácticas como el secado sanitario de estanques de cultivo, campañas de control sanitario y monitoreos sanitarios de rutina permitirán reducir la propagación de patógenos entre las diferentes zonas de cultivo del camarón, especialmente en un país con las particularidades de Costa Rica, donde las condiciones geográficas implican un alto riesgo debido 
a la cercanía de las fincas y la posible reutilización de las aguas provenientes del Golfo de Nicoya.

Pantoja \& Lightner (2014) indican que el futuro de la industria camaronícola, dependerá de la utilización de especies genéticamente mejoradas, libres de patógenos, y el uso tanto de antibacterianos como de antivirales. Por otro lado, para reducir los impactos mencionados con anterioridad, la bioseguridad surge como la medida de control y prevención más eficaz (Moss et al. 2012), misma conclusión obtenida por Morales et al. (2011) y Cuéllar-Anjel et al. (2008).

Se concluye que, durante el periodo de evaluación de la investigación para las zonas de estudio, se identificó la presencia de algunas de las principales patologías que afectan los cultivos de camarón a nivel mundial, mismos resultados que concordaron con los reportes emitidos por la OIE en los que se notificó desde el 2006 al 2011 las enfermedades WSSV, IHHNV y TSV (Salazar 2006); durante el 2012 se incluyó NHP (Rojas 2012) y del 2013 al 2015 se mencionó la presencia oficial de WSSV, IHHNV y NHP (Hernández 2015). En este sentido y al contar con tanta variedad de enfermedades asociada con prácticas de manejo ineficientes en algunos casos, el impacto de dichas patologías en la producción de camarón en Costa Rica ha generado altas mortalidades traducidas en pérdidas económicas de los camaronicultores. Esto ha sido poco investigado en el país y los estudios más recientes (Peña et al. 2013, Varela \& Peña 2013, 2014, 2015, 2016; Peña \& Varela 2015), sugieren la posibilidad de que se presente una situación difícil para la producción camaronera, tanto a mediano como a largo plazo.

Por otro lado, es determinante la estandarización de protocolos de bioseguridad y buenas prácticas de manejo en todas las fincas camaroneras, con la finalidad de reducir el ingreso de patologías provenientes de otras granjas, a la vez, buscar alternativas en el manejo de la calidad de las aguas para mantener un equilibrio en la dinámica de los organismos presentes en las aguas de cultivo (Lightner \& Pantoja 2001). Cabe resaltar, la necesidad de iniciar monitoreos epidemiológicos regulares para la identificación oportuna de la presencia de enfermedades de mayor riesgo para el cultivo de camarón en Costa Rica, cuya finalidad será la prevención y la activación de protocolos que permitan la reducción del riesgo en los estanques de cultivo. Cuéllar-Anjel et al. (2010) indican entre buenas prácticas de manejo, una adecuada preparación de los estanques antes de realizar la siembra y una adecuada verificación de la calidad de las postlarvas, aunado a controles estrictos en el manejo de la calidad del agua y el alimento; donde este último debe ser almacenado con las condiciones adecuadas para evitar la propagación de levaduras y el incremento de posibles vectores.

\section{Agradecimientos}

A la Universidad Técnica Nacional por el financiamiento de este proyecto, bajo el nombre de 'Prevalencia de enfermedades en Litopenaeus vannamei cultivado en Costa Rica'. Al Laboratorio Nacional de Servicios Veterinarios (LANASEVE) por facilitar el equipo para realizar los cortes histológicos y la realización de los análisis moleculares. A Carolina Marín del Laboratorio de Microbiología de la Estación de Biología Marina de la Universidad Nacional. A los productores de camarón por facilitar el acceso a las fincas camaroneras y donar los animales utilizados para los análisis ejecutados. Para el análisis estadístico se recibió el apoyo de Adrián Vargas, de la Escuela de Economía de la Universidad de Costa Rica.

\section{LITERATURA CITADA}

Alfaro R, M Guevara \& I Gonzáles. 2010. Prevalencia y distribución de los principales agentes etiológicos que afectan los langostinos silvestres en Tumbes, Perú. Revista Peruana de Biología 17(3): 359-364.

Braz RDS, da Silva CPRO, LG Reis, PCC Martins, MP de Sales \& RV Meissner. 2009. Prevalence of infectious hypodermal and hematopoietic necrosis virus (IHHNV) in Penaeus vannamei cultured in northeastern Brazil. Aquaculture 288(1): 143-146.

Bush AO, KD Lafferty, JM Lotz \& AW Shostak. 1997. Parasitology meets ecology on its own terms: Margolis et al. revisited. Journal of Parasitology 83(4): 575-583.

Chakrabarty U, A Mallik, D Mondal, S Dutta \& N Mandal. 2014. Assessment of WSSV prevalence and distribution of disease-resistant shrimp among the wild population of Penaeus monodon along the west coast of India. Journal Invertebrate Pathology 119: 12-18.

Claydon K, RAH Tahir, HM Said, MH Lakim \& W Tamat. 2010. Prevalence of shrimp viruses in wild Penaeus monodon from Brunei Darussalam. Aquaculture 308: 71 74.

Cuéllar-Anjel J. 2008. Métodos de diagnósticos de enfermedades en camarones marinos de cultivo. En: Morales V \& J CuéllarAnjel (eds). Guía técnica - Patología e inmunología de camarones penaeidos, pp 1-54. Programa CYTED Red IID Vannamei, Panamá.

Cuéllar-Anjel J. 2014. Métodos de diagnósticos de enfermedades en camarones penaeidos. En: Morales V \& J Cuéllar-Anjel (eds). Guía técnica. Patología e inmunología de camarones peneidos, pp. 21-92. OIRSA, Panamá.

Cuéllar-Anjel J, C Lara, V Morales, A De Gracia \& O García. 2010. Manual de buenas prácticas de manejo para el cultivo del camarón blanco Penaeus vannamei, 122 pp. OIRSA-OSPESCA, Panamá. 
Da Silva VA, F dos Santos, $S$ Bezerra, V Pedrosa, $P$ Mendes \& E Mendes. 2010. A multi-season survey for infectious myonecrosis in farmed shrimp, Litopenaeus vannamei, in Pernambuco, Brazil. Journal of Invertebrate Pathology 104: 161-165.

De Blas I \& A Muniesa. 2014. Vigilancia epidemiológica en camaronicultura. En: Morales V \& J Cuéllar-Anjel (eds). Guía técnica. Patología e inmunología de camarones peneidos, pp. 309-327. OIRSA, Panamá.

Flegel TW. 2012. Historic emergence, impact and current status of shrimp pathogens in Africa. Journal of Invertebrate Pathology 110(2): 174-183.

Guzmán FM, ZJ Molina, R Pérez, J Ibarra \& L Galavíz. 2009. Virus de la necrosis hipodérmica y hematopoyética infecciosa (IHHNV) y virus del síndrome de Taura (TSV) en camarón silvestre de la Laguna Madre, Golfo de México. Revista de Biología Marina y Oceanografía 44(3): 663-672.

Hernández BJ. 2015. Informe Anual de Salud Animal. Base de datos del Sistema mundial de información zoosanitaria (WAHIS Interface) - Versión 1. Organización Mundial de Sanidad Animal (OIE). <http://www.oie.int/wahis_2/public/ w a hid.ph p/R evi ew report/s e m e s tria 1/ review?year $=2015 \&$ semester $=0 \&$ wild $=0 \&$ country $=$ CRI\&this_ country_code $=$ CRI\&detailed $=1>$

Ibarra JC, L Galaviz \& ZJ Molina. 2007. Distribución de la bacteria causante de la necrosis hepatopancreática (NHPB) en cultivos de camarón blanco, Litopenaeus vannamei, en México. Ciencias Marinas 33: 1-9.

Lightner DV. 1996. A handbook of shrimp pathology and diagnostic procedures for diseases of cultured Penaeid shrimp, 26 pp. World Aquaculture Society, Baton Rouge.

Lightner DV. 2011. Virus diseases of farmed shrimp in the Western Hemisphere (the Americas): A review. Journal of Invertebrate Pathology 106: 110-130.

Lightner DV \& C Pantoja. 2001. Bioseguridad en el cultivo de camarones. Métodos para mejorar la camaronicultura en Centroamérica, pp. 123-166. <http://www.cesasin.com.mx/ CentroAmerica/7\%20Bioseguridad.pdf/>

Macías N, N Mañón, J Romero, E Camacho, M Magallanes, N Leyva, J Hernández, F Magallón, R Pérez, S Sánchez \& J Méndez. 2014. Prevalence of viral pathogens WSSV and IHHNV in wild organisms at the Pacific Coast of Mexico. Journal of Invertebrate Pathology 116: 8-12.

Morales MS. 2010. Enfermedades del camarón. Detección mediante análisis en fresco e histología, $180 \mathrm{pp}$. Trillas, México.

Morales MS \& B Goméz-Gil. 2014. Enfermedades bacterianas. In: Morales V \& J Cuéllar-Anjel (eds). Guía técnica. Patología e inmunología de camarones penaeidos, pp. 167-194. OIRSA, Panamá.

Morales MS, A Ruiz, A Pereira, VT Solís \& G Conroy. 2011. Prevalencia de enfermedades de camarón blanco (Litopenaeus vannamei) cultivados en ocho regiones de Latinoamérica. Revista Científica, Facultad de Ciencias Veterinarias de la Universidad del Zulia 21(5): 434-446.
Moss S, D Moss, S Arce, D Lightner \& J Lotz. 2012. The role of selective breeding and biosecurity in the prevention of disease in penaeid shrimp aquaculture. Journal of Invertebrate Pathology 110(2): 247-250.

Pantoja CR \& DV Lightner. 2014. Enfermedades virales del camarón. En: Morales V \& J Cuéllar-Anjel (eds). Guía técnica. Patología e inmunología de camarones penaeidos, pp 99-164. OIRSA, Panamá.

Peeler E. 2012. Cost and benefits of freedom from shrimp diseases in the European Union. Journal Invertebrate Pathology 110(2): 188-195.

Peña N. 2009. Práctica laboral y profesional realizada en producciones de engorde de camarón (Litopenaeus vannamei) en la zona de San Buenaventura de Colorado de Abangares, Guanacaste, Costa Rica. Práctica de bachiller en Ingeniería Agronómica con énfasis en Zootecnia, Universidad de Costa Rica, Sede Rodrigo Facio, 26 pp.

Peña N \& A Varela. 2015. Análisis histopatológico en Litopenaeus vannamei infectado con Vibrio parahaemolyticus. Agronomía Mesoamericana 26(1): 43-53.

Peña N, R Vargas \& A Varela. 2013. Productos naturales como estimuladores del sistema inmunológico de Litopenaeus vannamei, infectado con Vibrio parahaemolyticus. Agronomía Mesoamericana 24(1): 133-147.

Rojas G. 2012. Informe Anual de Salud Animal. Base de datos del Sistema mundial de información zoosanitaria (WAHIS Interface) - Versión 1. Organización Mundial de Sanidad Animal (OIE). <http://www.oie.int/wahis_2/public/ wahid.php/Reviewreport/semestrial/ review? year $=2012 \&$ semester $=0 \&$ wild $=0 \&$ country $=$ CRI\&this_country_code $=$ CRI\&detailed $=1>$

Salazar V. 2006. Informe Anual de Salud Animal. Base de datos del Sistema mundial de información zoosanitaria (WAHIS Interface) - Versión 1. Organización Mundial de Sanidad Animal (OIE) <http://www.oie.int/wahis_2/public/wahid.php/ Review report/semestrial/review year $=2006 \&$ semester= $0 \&$ wild $=0 \&$ country $=$ CRI\&this_country_code $=$ CRI\&detailed $=1>$

Stentiford GD. 2011. Diseases of commercially exploited crustaceans: Cross-cutting issues for global fisheries and aquaculture. Journal of Invertebrate Pathology 106(1): 3-5.

Varela A \& N Peña. 2013. El virus del Síndrome de las Manchas Blancas (WSSV): una revisión y su impacto en la camaronicultura costarricense. Revista de Ciencias Veterinarias 28(2): 51-69.

Varela A \& N Peña. 2014. Síndrome de mortalidad temprana (EMS/AHPNS) en camarones cultivados: Una revisión. Repertorio Científico 17(1): 25-30.

Varela A \& N Peña. 2015. Hepatopancreatitis Necrotizante asociada al Fenómeno del Niño, en cultivos de camarones del Golfo de Nicoya. Revista Repertorio Científico 18(1): 29-34. 
Varela A \& N Peña. 2016. Histopatología diferencial de tres enfermedades bacterianas que afectan el hepatopáncreas de camarones peneidos, Agronomía Mesoamericana 27(1): 73-80.
Yano Y, K Hamano, M Satomi, I Tsutsui, B Masatoshi \& D Aue-Umneoy. 2014. Prevalence and antimicrobial susceptibility of Vibrio species related to food safety isolated from shrimp cultured at inland ponds in Thailand. Food Control 38:30-36.

Recibido el 1 de julio de 2015 y aceptado el 8 de agosto de 2016

Editor: Claudia Bustos D. / col. Dr. Jorge Cuéllar Anjel 